University of Nebraska - Lincoln

DigitalCommons@University of Nebraska - Lincoln

USDA National Wildlife Research Center - Staff

Publications
U.S. Department of Agriculture: Animal and Plant Health Inspection Service

January 2005

\title{
Coyote movements and social structure along a cryptic population genetic subdivision
}

\author{
Benjamin N. Sacks \\ Wildlife and Ecology Unit, Veterinary Genetics Laboratory, School of Veterinary Medicine, University of \\ California \\ Brian R. Mitchell \\ Department of Environmental Science, Policy, and Management, University of California \\ Christen L. Williams \\ USDA, Wildlife Services, National Wildlife Research Center \\ Holly B. Ernest \\ Department of Population Health and Reproduction, School of Veterinary Medicine, University of \\ California
}

Follow this and additional works at: https://digitalcommons.unl.edu/icwdm_usdanwrc

Part of the Environmental Sciences Commons

Sacks, Benjamin N.; Mitchell, Brian R.; Williams, Christen L.; and Ernest, Holly B., "Coyote movements and social structure along a cryptic population genetic subdivision" (2005). USDA National Wildlife Research Center - Staff Publications. 59.

https://digitalcommons.unl.edu/icwdm_usdanwrc/59

This Article is brought to you for free and open access by the U.S. Department of Agriculture: Animal and Plant Health Inspection Service at DigitalCommons@University of Nebraska - Lincoln. It has been accepted for inclusion in USDA National Wildlife Research Center - Staff Publications by an authorized administrator of DigitalCommons@University of Nebraska - Lincoln. 


\title{
Coyote movements and social structure along a cryptic population genetic subdivision
}

\author{
BENJAMIN N. SACKS, ${ }^{*}$ BRIAN R. MITCHELL,+CHRISTEN L. WILLIAMS $\ddagger$ and HOLLY B. ERNEST*§ \\ *Wildife and Ecology Unit, Veterinary Genetics Laboratory, School of Veterinary Medicine, University of California, Davis, One \\ Shields Avenue, Davis, CA 95616-8744, USA, +Department of Environmental Science, Policy, and Management, 151 Hilgard Hall \\ \#3110, University of California, Berkeley, CA 94720-3110, USA, ¥USDA, Wildlife Services, National Wildlife Research Center, 4101 \\ LaPorte Avenue, Fort Collins, CO 80521, USA, §Department of Population Health and Reproduction, School of Veterinary Medicine, \\ University of California, Davis, Davis, CA 95616-8744, USA
}

\begin{abstract}
A recent region-wide study determined that the central California coyote (Canis latrans) population was genetically subdivided according to habitat bioregions, supporting the hypothesis that coyotes exhibit a dispersal bias toward their natal habitat type. Here, we further investigated this hypothesis using radio-collared coyotes captured on a $150-\mathrm{km}^{2}$ study site on the border of (i.e. overlapping) two bioregions (Great Valley and Cascade Mountains). As predicted, most coyotes were assigned (based on a priori genetic criteria) to genetic clusters corresponding to one of these two bioregions. All of those assigned to the Great Valley genetic cluster were caught in (and for the most part, remained in) the Great Valley bioregion. However, contrary to expectations, the coyotes assigned to the Cascades genetic cluster occurred commonly in both bioregions. Nearly all resident individuals on the study site, regardless of the particular bioregion, were assigned to the Cascades genetic cluster, whereas a sizable fraction of nonresident (transient or dispersing) coyotes caught in the Great Valley bioregion were assigned to the Great Valley cluster. Even among resident coyotes, interrelatedness of packs was greater within than between bioregions, and packs with territories overlapping both bioregions were more closely related to those with territories completely within the Cascades bioregion than territories completely within the Great Valley bioregion. Finally, direct estimates indicated that gene flow was twice as high from the Cascades bioregion to the Great Valley bioregion than in the reverse direction. Collectively, these findings reveal the anatomy of the genetic subdivision as beginning abruptly at the bioregion boundary and ending diffusely within the Great Valley bioregion.
\end{abstract}

Keywords: Canis latrans, coyote, dispersal, gene flow, habitat, microsatellites

Received 31 August 2004; revision received 3 December 2004; accepted 1 January 2005

\section{Introduction}

Recent methodological advances in spatial analysis of population genetic data (reviewed by Manel et al. 2003) have led to varying degrees of evidence for the occurrence of cryptic population genetic structure in continuously distributed terrestrial mammals (Carmichael et al. 2001; Ernest et al. 2003; Rueness et al. 2003; Sacks et al. 2004). 'Cryptic', for our purposes, implies discrete genetic sub-

Correspondence: B. N. Sacks, Fax:+1-530-752-3556; E-mail: bnsacks@ucdavis.edu divisions corresponding to borders between spatial units with no gaps in a species' distribution and no physical barriers to movement. Such cryptic subdivisions are of great interest both in terms of the behavioural and social processes they reflect and because of their potential role in ecological and evolutionary processes. An exciting implication of cryptic population structure is that animal populations, rather than being simple assemblages of individuals, are spatially organized at higher hierarchical levels than the family group. Such levels may correspond to higher-order social groupings such as neighbourhoods (Temeles 1994), or they may reflect interactions between ontogenetic 
tendencies in the individual or the physical landscape (Davis \& Stamps 2004), or both. Difficulties in tracking movements of large numbers of individuals have hampered the study of higher-order social organization and dispersal behaviour in large mammals and, until recently, lack of methods for spatial analysis of genetic data have likewise prevented visualization of cryptic population structure. Here, we merge field-based monitoring of coyote (Canis latrans) movements and relationships with a landscape genetic approach to examine more closely the social fabric of coyotes captured along the border between two habitats corresponding to a recently described cryptic population genetic subdivision in this species (Sacks et al. 2004).

In the earlier regional-scale study, Sacks et al. (2004) found that the central California coyote population was genetically subdivided into four groups along habitat breaks consistent with the a priori hypothesis that coyotes dispersed preferentially into habitat similar to their natal habitat. However, because that study used single capture locations of coyotes over a large portion of California, it lacked the focused information about individual coyote movements necessary to conclusively test the hypothesis. Moreover, even if the natal-habitat-biased dispersal hypothesis proves to be essentially correct, that is, that population genetic structure of coyotes ultimately arises from a tendency of coyotes to disperse into habitat similar to their natal habitat, the reality may be more complex. For example, coyotes are highly social, not only within packs (i.e. territorial family groups) but among them (Bekoff \& Wells 1986; Gese 2001). Although they commonly disperse over long distances (Harrison 1992), they frequently settle in nearby territories (Williams et al. 2003), suggesting neighbourhood structure could mediate any natal-habitat-biased dispersal tendencies. The strength of dispersal biases could also vary depending on the type or quality of natal habitat, possibly resulting in asymmetric patterns of gene flow. Understanding how behaviour, sociality, and landscape patterns interact in determining population structure is important in assessing their likely roles in ecological and evolutionary processes.

In this study, we investigated the behavioural underpinnings of earlier findings using additional, radio-collared coyotes from a relatively small site $\left(150 \mathrm{~km}^{2}\right)$, the Dye Creek Preserve (DCP), straddling the border of two habitat bioregions (Fig. 1). Our approach was twofold. First, we assigned each DCP coyote to one of the four central California genetic clusters identified by Sacks et al. (2004) and examined their habitat use in this context. Assignments of 98 DCP coyotes to genetic clusters was accomplished using prior information based on genotypes of 517 central California coyotes external to the DCP (including the 457 individuals used by Sacks et al. 2004). Symmetry of gene flow was also investigated between the two habitat bioregions. Second, we investigated the social cohesion of packs

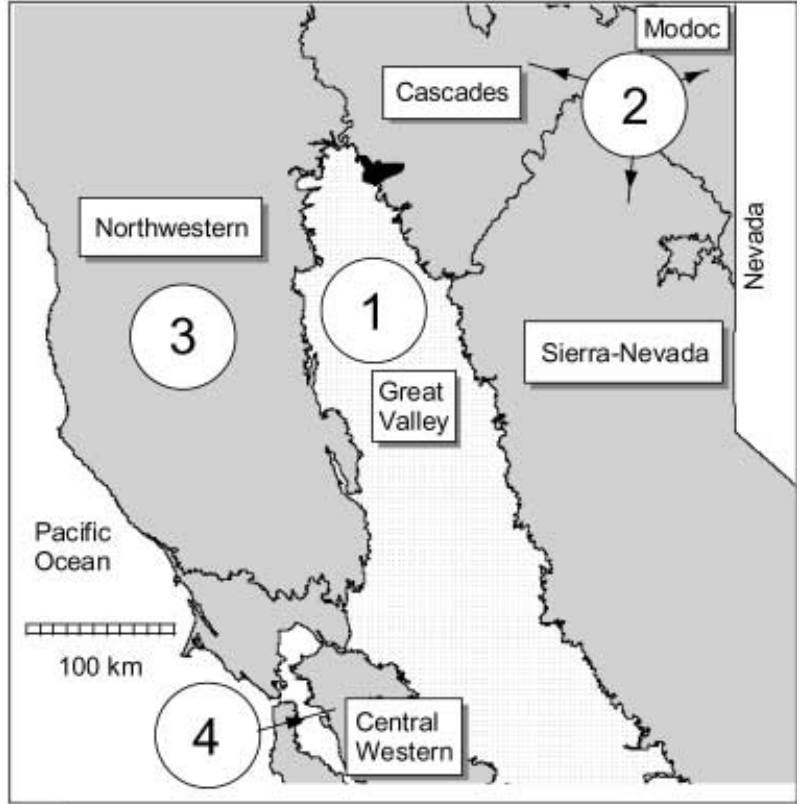

Flat valley habitat

Hilly and mountainous habitat

Dye Creek Preserve

Fig. 1 Map of the study area, illustrating the location of the Dye Creek Preserve on the boundary of the Great Valley and the Cascades bioregions. Four previously identified coyote genetic clusters corresponded to bioregions as follows: (1) Great Valley (2) Cascades, Sierra-Nevada, Modoc (3) Northwestern, and (4) Central Western (Sacks et al. 2004).

in relation to the habitat divide, irrespective of genetic cluster assignment.

\section{Materials and methods}

\section{Study area}

The DCP $\left(40.11^{\circ} \mathrm{N}, 122.04^{\circ} \mathrm{W}\right)$ is a $150-\mathrm{km}^{2}$ area located partly in the Cascades bioregion (CAS), characterized by blue-oak (Quercus douglassii) woodland and annual grassland vegetation on rolling hills varying in altitude from 150 to $710 \mathrm{~m}$ above sea level (a.s.l.) ('hill' habitat) and partly in the Great Valley bioregion (GV), flat terrain dominated by agricultural fields and grasslands (75 to $150 \mathrm{~m}$ a.s.l.; 'valley' habitat) (Hickman 1993; Mitchell 2004; Fig. 1). The exact boundary between these two bioregions was as defined by Hickman (1993).

\section{Field and laboratory methods}

Coyotes were captured alive using snares or padded-jaw foothold traps from March 1998 to July 2002, radio collared, and released. Blood and/or ear tissue were collected for 
DNA extraction. Coyotes were radio-tracked for up to 5 years $(\bar{x}=1.5$ years). Determination of each coyote's social status - resident (i.e. using a regular territory, including breeding adult, nonbreeding pack associate, pup) or transient (wandered widely, did not use a regular area) - and pack affiliation was described in detail by Mitchell (2004) and was based on space use (radiotelemetry data), behaviour observations (including social interactions), age, and reproductive condition (as observed at capture). Parentage tests were also used to aid in determination of pack affiliations (B. R. Mitchell, unpublished). In general, coyotes were considered residents if they occupied regular territories and transients if they did not. Animal care and use protocols were approved by the University of California, Berkeley (R139) and the United States Department of Agriculture, National Wildlife Research Center (QA 586).

Sample collection, DNA extraction, purification, and polymerase chain reaction (PCR) amplification procedures were as detailed by Sacks et al. (2004) and Williams et al. (2003), as were genotyping procedures, except that in this study, 13 of the loci (those used by Sacks et al. 2004) were genotyped using an ABI 3730 capillary DNA analyser. Hardy-Weinberg and linkage equilibria were assessed in the DCP coyotes using ARLEQUIN version 2.000 ( Schneider et al. 2000; Guo \& Thompson 1992) and GENEPOP version 3.3 (Raymond \& Rousset 1995), respectively. Hardy-Weinberg and linkage equilibrium tests for other central California coyotes were presented previously (Sacks et al. 2004).

\section{Assignment of DCP coyotes to regional clusters}

Assignment tests were performed in the program STRUCTURE 2.0 (Pritchard et al. 2000) based on genotypes at the 13 loci used by Sacks et al. (2004) (FH2001, FH2004, FH2010, FH2054, FH2079, FH2088, FH2096, FH2100, FH2161, FH2289, FH2328, FH2380, and FH2457; Breen et al. 2001). A total of 615 coyotes was used for this study. First, 517 central California coyotes (457 coyotes used by Sacks et al. 2004 and 60 additional specimens) external to DCP were assigned to one of four genetic clusters corresponding to four California bioregions (Fig. 1) based on 13 microsatellite loci (Sacks et al. 2004). This prior information was then used as per Pritchard \& Wen (2002) to assign 98 DCP coyotes to one of the four clusters. Assignments were defined conservatively as the most probable cluster. Additional analyses using a stricter criterion for assignment $(\geq 80 \%$ probability) did not qualitatively change results and are therefore not presented. Further, a second run performed on all 615 coyotes without using prior information produced nearly identical assignments and a third run assuming five clusters did not qualitatively improve the fit over the four-cluster model according to the log $\operatorname{Pr}(\mathrm{X} \mid \mathrm{K})$ or geographical criteria (Pritchard et al. 2000; Sacks et al. 2004).
Habitat use and residence on the DCP relative to cluster assignment

We tested the predictions that coyotes assigned to the GV cluster primarily used the valley and that those assigned to the CAS cluster primarily used the foothills. We did this both for capture locations and for last-known locations (e.g. radiotelemetry locations, mortality sites). The average time between capture and last known location was 1.5 years (range: 1-1874 days). Fisher exact tests were used to test the null hypothesis: coyote location (valley vs. hills) is independent of genetic cluster assignment.

\section{Directionality of gene flow}

We investigated symmetry of gene flow between habitats among the 98 DCP coyotes in two ways. First, we compared genetic admixture between genetic clusters (GV, CAS) and between habitat-use categories (hills, valley, both, based on first and last-known locations). If gene flow was asymmetrical, admixture should have been greatest on average among individuals in the cluster or habitat that received the highest proportion of migrants from the other(s). The extent of an individual's genetic admixture was estimated based on the $Q$ values (estimated proportions of ancestry) calculated in the STRUCTURE analyses (Pritchard et al. 2000). Although four $Q$ values are calculated for each individual (one for each genetic cluster), we used only the $Q$ values corresponding to each individual's cluster assignment (i.e. their largest $Q$ value). Because of the highly non-normal nature of $Q$ distributions, statistical differences were assessed using a nonparametric Kolmogorov-Smirnov test (for the two-group comparison) and a Kruskal-Wallis test (for the three-group comparison), both performed in SYSTAT version 9.0 (SPSS Inc.) (Zar 1999).

To investigate gene flow between genetic clusters and between habitat-use categories more directly, we used the program BAYESASS version 1.2 (Wilson \& Rannala 2003). This program uses a Bayesian approach that produces estimates of recent migration rates between groups in each direction without depending on potentially unrealistic assumptions such as equilibrium between gene flow and random drift. Default settings were selected for all parameters.

\section{Pairwise relatedness of individuals and packs with respect to habitat}

These analyses focused on resident packs as the sample units and compared social connections among their territories within vs. between habitats. We used the 98 DCP coyotes and the seven new loci (CXX2235, FH2140, CXX140, FH2062, FH2137, FH2159, FH2441; Breen et al. 2001) in addition to the 13 loci used by Sacks et al. (2004; given 
previously) for a total of 20 loci. We examined the relationships among packs in two ways. First, we calculated the relatedness, $R$, between all pairs of individuals and determined linkages between territories in terms of related individuals, defined as $R>0.25$ (implies an estimate that $>25 \%$ of genes are shared) (Queller \& Goodnight 1989). We chose 0.25 as the cutoff value because this corresponds to the expected value for second-order relatives and was sufficiently low to include most first-order relatives (expected $R=0.50$ ) while excluding most nonrelatives. For example, $97 \%$ of known first-order relatives (average $R \pm \mathrm{SD}=0.44 \pm$ $0.10, n=32$ ) had $R>0.25$ and of $95 \%$ of nonfirst-order relatives (but possibly including some second-order relatives) $(0.00 \pm 0.13, n=88)$ had $R<0.25$. We used RELATEDNESS 5.0 (http://www.gsoftnet.us/GSoft.html) to calculate $R$. We used Yates-corrected chi-squared goodness-of-fit tests to determine whether the frequency of linkages connecting territories within the same habitat vs. between habitats differed proportionally from chance expectation. To assess the potentially confounding effect of geographical distance, we tested whether linkages occurred more frequently than expected by chance in adjacent territories using a Yates-corrected chi-squared goodness-of-fit test. Expected numbers were calculated as the total number of interpack relative-pairs multiplied by the proportion of all possible pairings within the same habitat (former analysis) or in adjacent territories (latter analysis).

The use of $R$ values was useful in that we could pinpoint social relationships among packs directly. However, most pairs of individuals were not first- or second-order relatives and $R$ values do not indicate more distant relationships. Therefore, we also calculated pairwise $\hat{F}_{\mathrm{ST}}$ values among packs. These estimates were expected to be biased, in an absolute sense, because of high levels of within-pack relatedness, but nevertheless should have provided an unbiased index of relative genetic distance among packs. We investigated partial correlations among pairwise distance (expressed as $\hat{F}_{\mathrm{ST}} /\left(1-\hat{F}_{\mathrm{ST}}\right)$, Slatkin 1995) matrices calculated from eight packs (those with $\geq 3$ members genotyped), using a multiple factor Mantel permutation test (Smouse et al. 1986). We wished to determine whether genetic distance was greater between packs from different bioregions than between packs from the same bioregion, over and above that expected because of geographical distance between territories. Independent variable matrices were of pack distance and bioregion. Pack distance was measured in numbers of territories separating packs (range 1-5). The bioregion matrix was composed of zeros and ones, where 0 corresponded to packs in the same bioregion and 1 corresponded to packs in different bioregions. In these analyses, the partial correlation coefficient between pack distance and bioregion effectively controlled for effects of pack distance, such that its significance would support the hypothesis that bioregions accounted for genetic distance over and above that explained by pack distance alone. We calculated the genetic distance matrix and performed Mantel tests using ARLEQUIN (Schneider et al. 2000).

Some packs had territories that overlapped both bioregions. Therefore, we performed the individual-based (i.e. $R$ ) and pack-based (i.e. $\hat{F}_{\mathrm{ST}}$ ) analyses twice, once considering packs with territories overlapping both habitats to be in the valley and a second time considering packs with territories overlapping both habitats to be in the hills. To compensate for the possible inflation of type I error rates caused by multiple comparisons, we used a Bonferroni correction (i.e. doubling $P$ values).

\section{Terminology}

To avoid confusion, we used the abbreviations 'CAS' and ' $G V^{\prime}$ ' strictly to refer to genetic cluster assignments and use the terms 'hill' and 'valley' strictly to refer to the physical location of coyotes (i.e. captures, final locations, territories). Nevertheless, 'hills' implies the Cascades bioregion and 'valley' implies the Great Valley bioregion.

\section{Results}

\section{Hardy-Weinberg and linkage equilibria in DCP coyotes}

We detected 214 alleles among the 20 loci (4-23 alleles each) in the 98 DCP coyotes. Three loci (FH2001, FH2140, FH2441) were significantly out of Hardy-Weinberg equilibrium after correcting for multiple comparisons. In all three cases, observed heterozygosity (average $=0.69$ ) was lower than expected heterozygosity (0.85). Average expected heterozygosity among the 20 loci was 0.80 (range $=0.55-$ 0.91). Of 190 pairs of loci, eight showed significant linkage disequilibrium after correcting for multiple comparisons (CXX140-FH2054, FH2004-FH2079, FH2088-FH2161, FH2010FH2328, FH2088-FH2328, FH2289-FH2441, FH2140-FH2457, FH2289-FH2457). Loci were not physically linked in any of these cases (Neff et al. 1999). These instances of HardyWeinberg and linkage disequilibrium were consistent with population substructure in the DCP sample.

\section{Habitat use and residence on the DCP relative to genetic cluster assignment}

Indeed, the DCP sample did not reflect a panmictic population. Of the 98 DCP coyotes genotyped, 19 were assigned to the GV cluster, 66 were assigned to the CAS cluster (equivalent to the Sierra Nevada/Cascades/Modoc cluster; Sacks et al. 2004), and 13 were assigned to the other two clusters (central western, northwestern). All 19 GV coyotes were initially captured in the valley section of DCP (i.e. no GV coyotes were initially captured in the hills portion 

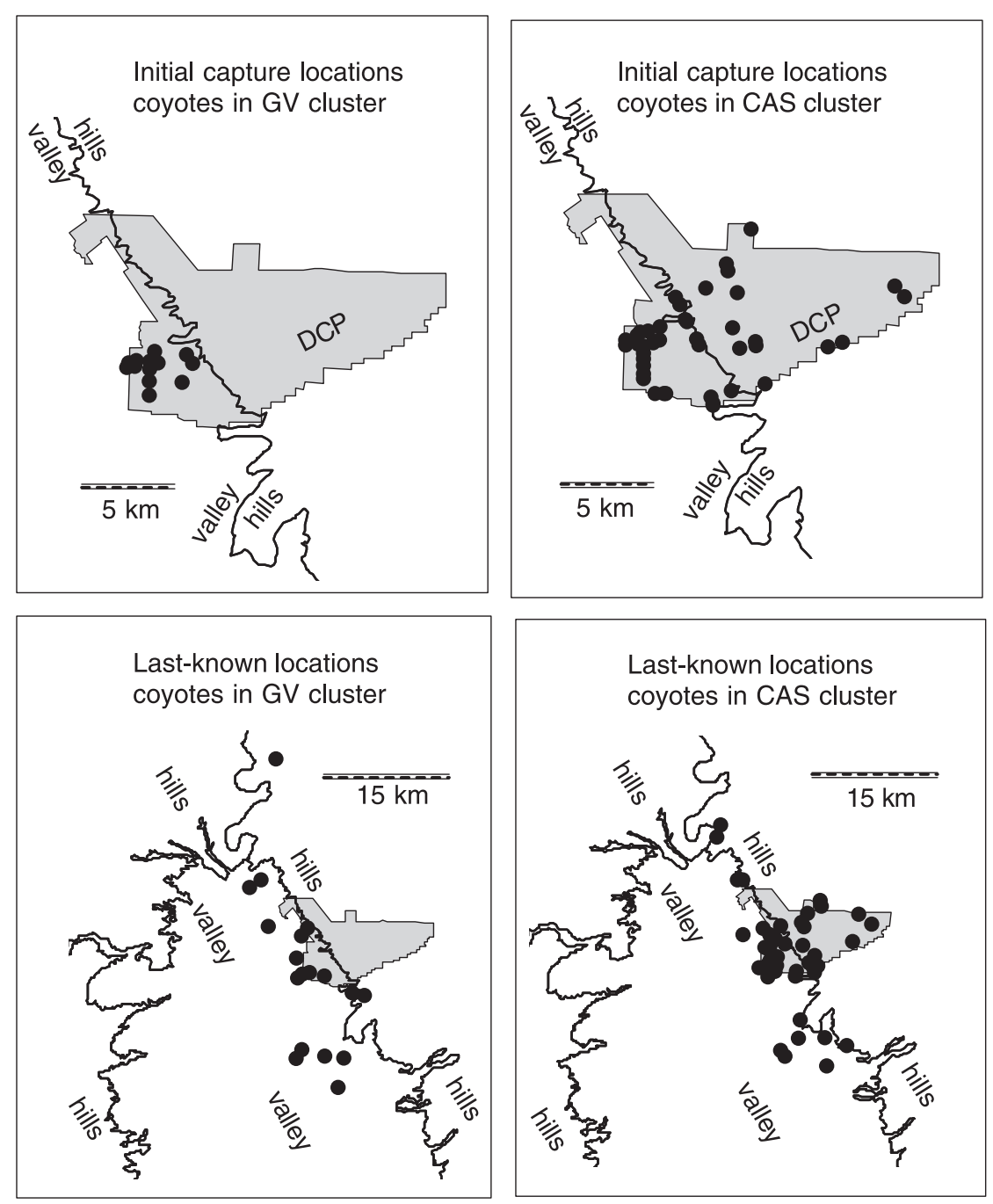

Fig. 2 Initial capture locations (top graphs) and last known locations (bottom graphs) of coyotes (black dots) assigned to Great Valley (GV, left graphs, $n=19)$ and Cascades (CAS, right graphs; $n=66$ ) genetic clusters. Locations are shown relative to the Dye Creek Preserve (DCP, shown in grey) and hill and valley habitat types (separated by tortuous line). All initial captures of GV coyotes were in valley habitat and their final locations were scattered widely, whereas initial captures of CAS coyotes were in both habitats and their final locations tended to remain on the DCP. Note: the lack of locations in the hills outside of the DCP was caused by radiotelemetry problems in this terrain and was not indicative of lack of coyote use. of DCP) (Fig. 2). In contrast, initial capture locations of the 66 CAS coyotes were split between valley (66\%) and hills (34\%) sections of DCP (Fig. 2). This difference between GV and CAS coyotes in capture habitat was highly significant (Fisher exact $P<0.001$ ). Similarly, last known locations of GV coyotes were more frequently in the valley (89\%; Fig. 2) than were those of CAS coyotes (72\%; Fig. 2; Fisher exact $P=0.08)$.

Interestingly, final locations of GV coyotes were more dispersed than those of CAS coyotes (Fig. 2), suggesting that GV coyotes primarily originated from elsewhere in the valley (i.e. outside of the DCP) and were initially captured while passing through the DCP. Indeed, of 30 residents on DCP (classified by radiotelemetry), one was a GV coyote and 26 were CAS coyotes (three were assigned to other clusters), whereas 54 transient coyotes (or residents outside of DCP) were more evenly split between GV (31\%) and CAS $(69 \%)$ clusters (Fisher exact $P<0.01$ ). Eight transients were assigned to other clusters and six coyotes lacked sufficient radiotelemetry data to be classified as residents or transients. The single GV coyote classified as a resident was paired with a CAS male and occupied a territory in the valley portion of DCP.

Overall, half of the 98 DCP coyotes had $Q$ values (i.e. estimated proportion of ancestry from the assigned cluster) $>90 \%$, and two-thirds of the sample had $Q$ values $>80 \%$. The remaining one-third of $Q$ values was spread approximately evenly between 0.25 and 0.80 . However, distributions of $Q$ values differed between CAS and GV clusters $\left(D_{\max }=0.39 ; P=0.02\right)$, with CAS coyotes tending to exhibit less admixture than GV coyotes (Fig. 3). Similarly, when analysed by habitat use, hill coyotes (i.e. initially captured and last located in the hills) showed less admixture (19\% individuals with $Q<0.80$ ) than valley coyotes (31\% individuals with $Q<0.80$ ), which had less admixture than coyotes initially captured in one habitat but last located in the other (48\% individuals with $Q<0.80$ ), although these differences were not significant $\left(H_{2}=1.66 ; P=0.43\right)$.

Estimated migration rate $( \pm S D)$ from the CAS cluster to the GV cluster $(0.32 \pm 0.02)$ was nearly twice of that from 

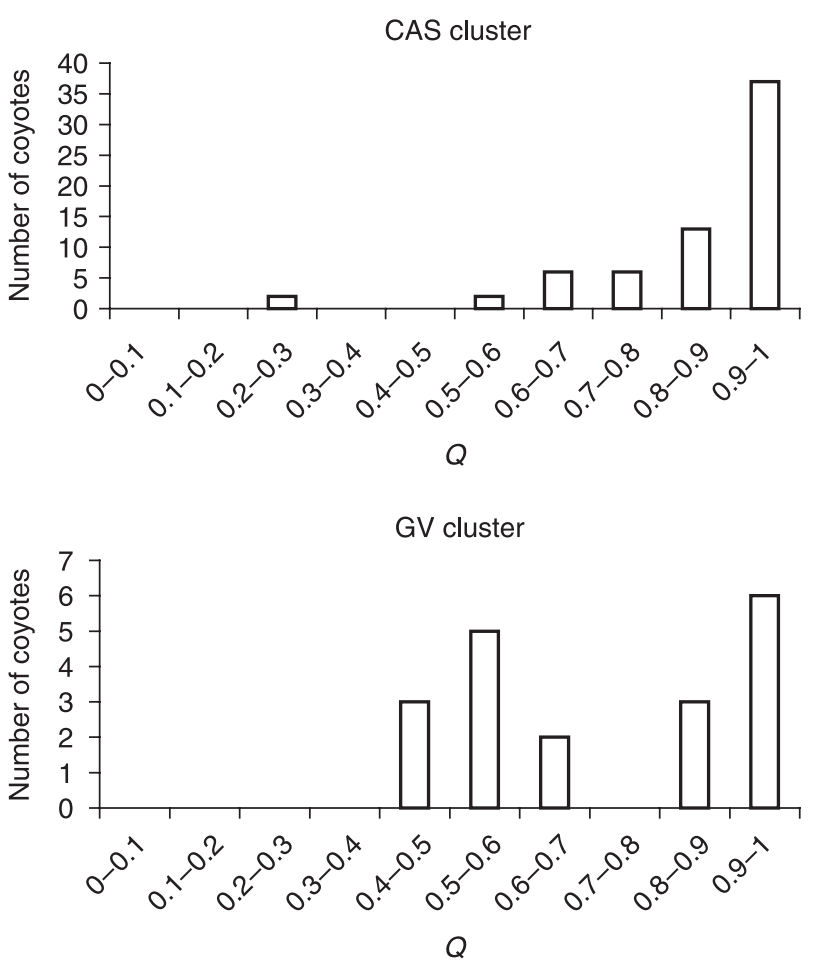

Fig. 3 Distributions of $Q$ values (estimated proportion of ancestry from the assigned cluster) of coyotes captured at Dye Creek Preserve assigned to CAS $(n=66)$ and GV $(n=19)$ genetic clusters. The greater proportion of low $Q$ values among GV than CAS coyotes indicates greater admixture among coyotes in the GV cluster.

the GV cluster to the CAS cluster $(0.18 \pm 0.03)$. Similarly, estimated migration rate from the hills to the valley $(0.26 \pm 0.02)$ was twice of that from the valley to the hills $(0.13 \pm 0.04)$.

\section{Pairwise relatedness of individuals and packs with respect to habitat}

We found 14 pairs of interpack relatives (Fig. 4). When four territories that straddled valley and hill habitats were pooled with four hill territories (i.e. straddling territories were assumed to be hill packs that spilled out into the valley), there were 11 within-habitat pairs of relatives, which was more than expected by chance $(n=6.4$ withinhabitat relatives; $\chi_{1}^{2}=3.70$, Bonferroni-corrected $P=0.056$ ). When straddling territories were pooled with six valley territories, however, there was no significant difference between numbers of observed and expected within-habitat pairs of relatives $\left(\chi_{1}^{2}=0.02\right.$, Bonferroni-corrected $P>0.88$ ). These results suggest that territories overlapping or completely within the hills were socially distinct from those completely within the valley. Excluding straddling territories, there were no instances of relative pairs between valley

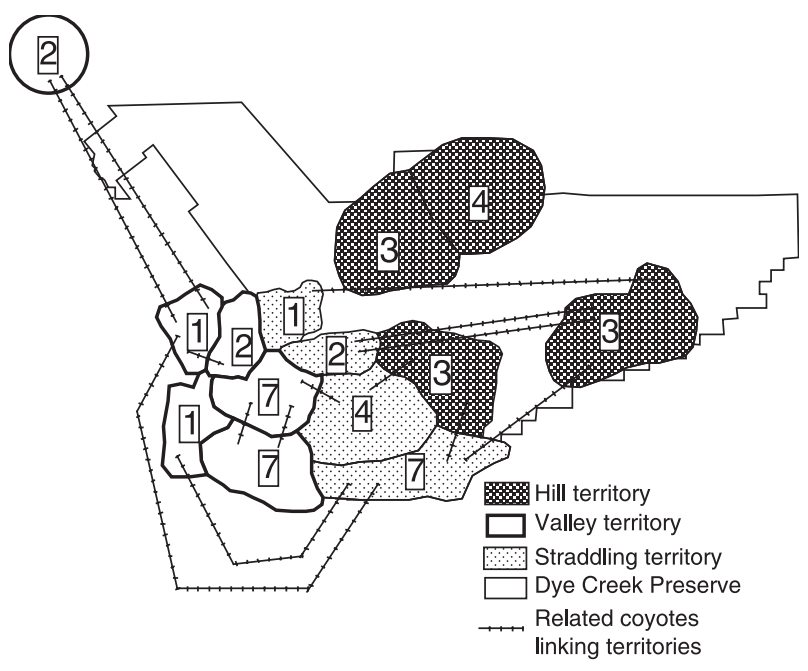

Fig. 4 Territories of radio-collared coyotes in and around the Dye Creek Preserve with connecting lines to indicate an individual in one pack related to an individual in another pack $(R>0.25)$. Numerals indicate numbers of individuals genotyped in each pack. No coyote from a valley territory had a relative in a hill territory, although territories straddling the boundary between hill and valley habitats shared relatives with coyotes in both habitats.

and hill territories compared to five instances of withinhabitat relative pairs. Of the 14 pairs of relatives, six instances were between adjacent territories and eight were between nonadjacent territories, which did not differ significantly from chance expectations $\left(3.2,10.8\right.$, respectively; $\chi_{1}^{2}=2.26$, $P=0.13$ ), suggesting interpack distance was not an important confounding variable in this situation.

Genetic distance $\left(\hat{F}_{\mathrm{ST}}\right)$ also was greater between packs in different bioregions than between packs in the same bioregion. When territories straddling bioregions were considered hill territories, this difference was significant (Fig. 5; average $\hat{F}_{\mathrm{ST}}=0.08$ within bioregions vs. $\hat{F}_{\mathrm{ST}}=0.15$ between bioregions; $r_{\mathrm{Y} 2-1}=0.14$, Bonferroni-corrected $P=$ 0.046). When territories straddling bioregions were considered valley territories, the difference was less pronounced (average $\hat{F}_{\mathrm{ST}}=0.10$ within bioregions vs. 0.13 between bioregions) and nonsignificant (Bonferroni-corrected $P=0.12$ ). There were no significant correlations between $\hat{F}_{\mathrm{ST}}$ and pack distance in terms of either univariate or partial correlation coefficients and regardless of whether packs with territories straddling bioregions were considered valley or hill packs $(P>0.70)$. Thus, again, geographical distance appeared irrelevant on the scale of this study.

Although sample sizes were too low for statistical comparison, it is worth noting that coyotes from hill packs had the highest average $Q$ value (0.92, range: $0.79-0.97)$, followed those from straddling packs $(0.86$, range: $0.56-0.95)$, and then those from valley packs $(0.82$, range: $0.48-0.98$ ). 


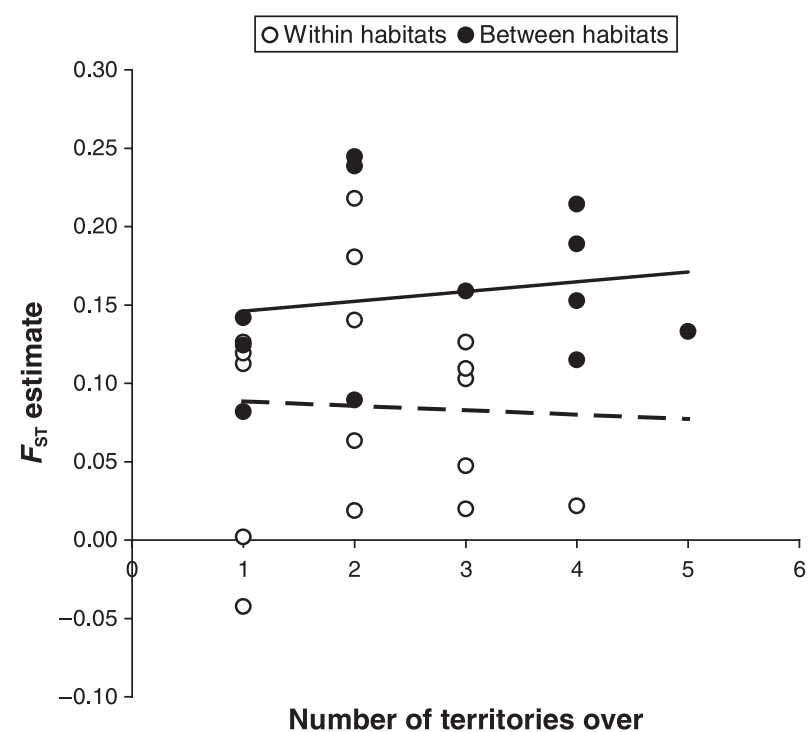

Fig. 5 Pairwise $\hat{F}_{\mathrm{ST}}$ between packs within and between habitats as a function of interpack distance. The difference in the elevations of the trend lines indicates a difference in within-habitat (dashed line) vs. between-habitat (solid line) $\hat{F}_{\mathrm{ST}}$ values; that these lines are approximately horizontal indicates no relationship between $\hat{F}_{\mathrm{ST}}$ and interpack distance. Corresponding Mantel test statistics reported in the text were based on linearized $\hat{F}_{\mathrm{ST}}, \hat{F}_{\mathrm{ST}} /\left(1-\hat{F}_{\mathrm{ST}}\right)$.

\section{Discussion}

Several recent coarse-scale studies have presented evidence or argument for the occurrence of habitat-related cryptic population genetic subdivisions in terrestrial vertebrates (Carmichael et al. 2001; Ernest et al. 2003; Rueness et al. 2003; Geffen et al. 2004; Sacks et al. 2004; Stenseth et al. 2004). However, there is little empirical evidence for any particular behavioural, social, or demographic cause of these subdivisions. At the other end of the spectrum, many studies have focused on the ontogeny of habitat-selection behaviour of individuals (reviewed by Davis \& Stamps 2004), but largely without regard to the population-level consequences of it. To extract a general understanding applicable to evolutionary theory, it is imperative to combine coarse landscape genetic approaches with fine-scale behavioural studies as we have attempted here.

Our study followed up the regional study by Sacks et al. (2004), which provided qualitative evidence that coyotes selectively dispersed to habitats similar to their natal habitats. Because of the necessarily coarse sampling, the previous study did not provide much resolution of the nature of the cryptic subdivisions. For example, because coyotes used in that study were ones that had been killed upon their initial capture, it was not possible to differentiate residents from those just passing through, e.g. during dispersal. In general, coyotes range widely and tend to be most vulnerable to capture when they are away from their territories or dispersing (Sacks et al. 1999a); it is therefore likely that many of these coyotes were caught far from their birth or breeding sites. Genetic structure stems from animal movements only in so far as the animals settle and breed. Therefore, it is important not only to understand how habitat affects the movements of individuals but, more directly, how it affects where they settle and reproduce. In this study, we radio-collared coyotes, which enabled us to distinguish residents from transients or dispersers, to map territories relative to habitat types, and to determine the relatedness among packs with respect to habitat divides.

First, our findings strengthened the conclusions by Sacks et al. (2004) that genetic structure of central California coyotes corresponds to habitat breaks and that this pattern relates to natal-habitat-biased dispersal. Although the coyotes in this study captured in the valley portion of the $\mathrm{DCP}$ were assigned commonly to both GV and CAS genetic clusters, this stood in stark contrast to the coyotes captured in the hill portion of the study area, none of which were assigned to the GV. Additionally, the DCP was quite distant from most sampling sites in the Sierra Nevada/ Cascades bioregion used by Sacks et al. (2004), making it a highly informative and independent validation of earlier findings.

To our knowledge, ours is the only study to explore the anatomy of a cryptic population genetic subdivision on a fine scale. An especially interesting finding of this study was an asymmetry with respect to coyote movement and gene flow between habitats. This asymmetry was supported consistently from several lines of evidence. First, the GV coyotes strongly avoided the hill habitat, whereas the CAS coyotes more commonly entered the valley habitat. Second, coyotes assigned to the GV genetic cluster tended to exhibit more admixture than those assigned to the CAS cluster. Likewise, coyotes located in valley habitat (regardless of genetic cluster assignment) tended to exhibit greater admixture than those located in hill habitat, although this trend was not statistically significant. Admixture tended also to be higher in packs resident in the valley portion of the DCP than in packs resident in the hill portion of the study area. Finally, direct estimates indicated approximately twice as much gene flow from the CAS cluster to the GV cluster and from the hills to the valley than in the reverse directions.

There are several possible explanations for the observed asymmetry in movement and gene flow between hill and valley habitats. One possibility is that hilly terrain may constitute a more complex environment than flat (valley) terrain, requiring greater sensory acuity. If so, coyotes may be better able to acclimate from hilly terrain to flat terrain than vice versa. Alternatively, or additionally, the valley may generally represent higher quality habitat than the hills and could therefore draw coyotes from the hills. For example, during summer, water is extremely scarce in the 
hills but, because of agricultural irrigation, is relatively abundant in the valley (B.R. Mitchell, personal observation), such that prey biomass is likely to be greater per unit area in the valley than in the hills. Coyote territories were somewhat smaller on average in the valley than in the hills (even more so than indicated in Fig. 4 if topography is accounted for), suggesting that resources may well have been denser in the valley. Further, there were several instances of valley packs sharing relatives, indicating short-distance dispersal within the valley. However, no nonstraddling hill packs were linked through relative pairs, suggesting that hill coyotes were less likely to disperse to nearby locations in the hills except to territories overlapping the valley.

Regardless of the reasons for the asymmetries in movement between habitats, it is important to note that even in the hill-to-valley direction, dispersal appeared to be slowed by the habitat break. That is, the pairwise relatedness and pack genetic distance analyses indicated that there was a tendency within the resident population (primarily CAS coyotes) for social units to situate on one or the other side of the boundary. For example, packs with territoriesstraddling habitats were connected through relatives to packs in both habitats but no packs solely in one habitat shared a relative with a pack solely in the other habitat. These patterns suggest that coyotes readily disperse from the hills to territories that include both habitats, and that the offspring of these straddling packs, which will have been exposed to both habitats, may readily disperse to territories in valley habitat. However, coyotes apparently did not disperse from interior hill territories to interior valley locations.

Another interesting observation in this study was that individuals assigned to the GV cluster were rarely resident on the valley portion (or hill portion) of the DCP. Coyotes in the valley just $30 \mathrm{~km}$ to the southwest of DCP were primarily assigned to the GV (Sacks et al. 2004), indicating that the relative proportions of GV and CAS resident coyotes changed substantially between the valley, where it abuts the bioregion boundary, and a little further into the valley interior. A possible explanation for how CAS coyotes could dominate the valley habitat directly adjacent to the bioregion boundary is if coyotes from straddling territories, which were genetically clustered with coyotes from interior hills (i.e. CAS coyotes) but exposed to both hill and valley vegetation, perceived their natal habitat based on the prey base as opposed to vegetation as a primary cue. Prey as a habitat cue has also been put forth as an explanation for population subdivision in wolves (Canis lupus) (Carmichael et al. 2001).

At DCP, the prey base associated with the hills extended into the valley for some distance. In particular, wild pigs (Sus scrofa) and, for part of the year, deer (Odocoileus hemionus), were associated with the hill habitat but frequently moved into the adjacent valley areas, e.g. to find water (especially in the summer; B. R. Mitchell, unpublished). Analysis of coyote scats indicated that these ungulates composed a seasonally important part of the diet in valley areas of the DCP as well (Barrett 1983; B. R. Mitchell, unpublished). Other than cattle, which were unlikely to compose a large part of the coyote diet, ungulate prey was essentially unavailable to coyotes further into the valley. Predation on ungulates by coyotes is a specialized behaviour that less experienced individuals tend to avoid (Gese \& Grothe 1995; Sacks et al. 1999b; Sacks \& Neale 2002). Therefore, it is conceivable that in valley areas adjacent to hills containing ungulate prey, CAS coyotes (born in or near the hills) hold a competitive advantage over GV coyotes (born in areas without ungulate prey). It would be informative in future studies to determine the diets of individual coyotes (e.g. via use of stable isotopes) with respect to genetic cluster assignment. Additionally, domination of the valley section of the DCP by CAS coyotes could be reinforced by social cohesion if, for example, territory establishment is better tolerated by neighbours that are closely related (Temeles 1994; Girman et al. 1997).

\section{Conclusions}

Our study has shown that cryptic genetic subdivisions in terrestrial carnivores can be sufficiently sharp to disrupt social fabric and be apparent at the smallest relevant spatial scale, that of the neighbourhood. We have provided further evidence that natal experience is likely to be important in limiting an individual's habitat selection during dispersal. However, the observed asymmetry in movements, gene flow, and settlement between habitats indicates that natal-habitat-biased dispersal in its simplest formulation may be insufficient to describe the complexity of cryptic population subdivisions, at least in the present case. It seems that overall habitat quality and social cohesion may be important contributors as well. Further, although beyond the scope of the present study, demographic aspects also could play a role, as has been suggested for other systems (Stenseth et al. 2004). We are optimistic that future work combining fine-scale field study of individuals and family groups with landscape genetic approaches will bring us closer to understanding the emergence of population genetic structure from animal behaviour, and that this knowledge will significantly advance our understanding of evolutionary processes.

\section{Acknowledgements}

We thank numerous people for field assistance, especially C. Anderson, M. Christianson, A. Crook, A. Crupi, M. Ebinger, B. Enticknap, E. Sequin, J. Shannon, L. Shannon, D. Simpson, and E. York. Additionally, S. Brown, A. Irish, and K. Records provided 
valuable laboratory assistance. Funding was provided by the United States Department of Agriculture/Animal Plant Health Inspection Service/Wildlife Services/National Wildlife Research Center, UC Davis Veterinary Genetics Laboratory (VGL), the UC Davis Genetic Resources Conservation Program, and the USDA/ APHIS Science Fellowship program (CW). We also thank Mike Jaeger, Niels Pedersen, and numerous VGL personnel for advice and support. J. C. C. Neale and three anonymous reviewers provided helpful comments on earlier drafts of this manuscript.

\section{References}

Barrett RH (1983) Food habits of coyotes, Canis latrans, in eastern Tehama County, California. California Fish and Game, 69, 184-186. Bekoff M, Wells MC (1986) Social ecology and behavior of coyotes. Advances in the Study Behavior, 16, 251-338.

Breen M, Jouquand S, Renier C et al. (2001) Chromosome-specific single-locus FISH probes allow anchorage of an 1800-marker integrated radiation-hybrid/linkage map of the domestic dog genome to all chromosomes. Genome Research, 11, 1784-1795.

Carmichael LE, Nagy JA, Larter NC, Strobeck C (2001) Prey specialization may influence patterns of gene flow in wolves of the Canadian Northwest. Molecular Ecology, 10, 2787-2798.

Davis JM, Stamps JA (2004) The effect of natal experience on habitat preferences. Trends in Ecology and Evolution, 19, 411-416.

Ernest HE, Boyce WM, Bleich VC, May B, Stiver SJ, Torres SG (2003) Genetic structure of mountain lion (Puma concolor) populations in California. Conservation Genetics, 4, 353-366.

Geffen E, Anderson MJ, Wayne RK (2004) Climate and habitat barriers to dispersal in the highly mobile grey wolf. Molecular Ecology, 13, 2481-2490.

Gese EM (2001) Territorial defense by coyotes (Canis latrans) in Yellowstone National Park, Wyoming: who, how, where, when, and why? Canadian Journal of Zoology, 79, 980-987.

Gese EM, Grothe S (1995) Analysis of coyote predation on deer and elk during winter in Yellowstone National Park, Wyoming. American Midland Naturalist, 133, 36-43.

Girman DJ, Mills MGL, Geffen E, Wayne RK (1997) A molecular genetic analysis of social structure, dispersal, and interpack relationships of the African wild dog (Lycaon pictus). Behavioral Ecology and Sociobiology, 40, 187-198.

Guo SW, Thompson EA (1992) Performing the exact test of Hardy-Weinberg proportion for multiple alleles. Biometrics, 48, 361-372.

Harrison DJ (1992) Dispersal characteristics of juvenile coyotes in Maine. Journal of Wildife Management, 56, 128-138.

Hickman JC ed. (1993) The Jepson Manual: Higher Plants of California. University of California Press, Berkeley.

Manel S, Schwartz MK, Luikart G, Taberlet P (2003) Landscape genetics: combining landscape ecology and population genetics. Trends in Ecology and Evolution, 18, 189-197.

Mitchell BR (2004) Coyote vocal communication and its application to the selective management of problem individuals. PhD Dissertation, University of California, Berkeley.

Neff MW, Broman KW, Mellersh CS et al. (1999) A second-generation genetic linkage map of the domestic dog, Canis familiaris. Genetics, 151, 803-820.

Pritchard JK, Stephens M, Donnelly P (2000) Inference of population structure using multilocus genotype data. Genetics, 155, 945-959.

Pritchard JK, Wen W (2002) Documentation for STRUCTURE software: Version 2. Available from http://pritch.bsd.uchicago.edu.
Queller DC, Goodnight KF (1989) Estimating relatedness using genetic markers. Evolution, 43, 258-275.

Raymond M, Rousset F (1995) GENEPOP (version 1.2): population genetics software for exact tests and ecumenicism. Journal of Heredity, 86, 248-249.

Rueness EK, Jorde PE, Hellborg L, Stenseth NC, Ellegren H, Jakobsen KS (2003) Cryptic population structure in a large, mobile mammalian predator: the Scandinavian lynx. Molecular Ecology, 12, 2623-2633.

Sacks BN, Neale JCC (2002) Foraging strategy of a generalist predator toward a special prey: coyote predation on sheep. Ecological Applications, 12, 299-306.

Sacks BN, Blejwas KM, Jaeger MM (1999a) Relative vulnerability of coyotes to removal methods on a northern California ranch. Journal of Wildlife Management, 63, 939-949.

Sacks BN, Brown SK, Ernest HB (2004) Population structure of California coyotes corresponds to habitat-specific breaks and illuminates species history. Molecular Ecology, 13, 12651275.

Sacks BN, Jaeger MM, Neale JCC, McCullough DR (1999b) Territoriality and breeding status of coyotes relative to sheep predation. Journal of Wildlife Management, 63, 593-605.

Schneider S, Roessli D, Excoffier L (2000) ARLEQUIN version 2.000: a software for population genetics analysis. Genetics and Biometry Laboratory, University of Geneva, Switzerland.

Slatkin M (1995) A measure of population subdivision based on microsatellite allele frequencies. Genetics, 139, 457-462.

Smouse PE, Long JC, Sokal RR (1986) Multiple regression and correlation extensions of the Mantel test of matrix correspondence. Systematic Zoology, 35, 627-632.

Stenseth NC, Ehrich D, Rueness EK et al. (2004) The effect of climatic forcing on population synchrony and genetic structuring of the Canadian lynx. Proceedings of the National Academy of Sciences of the United States of America, 101, 6056-6061.

Temeles EJ (1994) The role of neighbours in territorial systems: when are they 'dear enemies'? Animal Behaviour, 47, 339-350.

Williams CL, Blejwas KM, Johnston JJ, Jaeger MM (2003) Temporal genetic variation in a coyote (Canis latrans) population experiencing high turnover. Journal of Mammalogy, 84, 177-184.

Wilson GA, Rannala B (2003) Bayesian inference of recent migration rates using multilocus genotypes. Genetics, 163, 1177-1191.

Zar JH (1999) Biostatistical Analysis, 4th edn. Prentice Hall, Upper Saddle River, New Jersey.

Ben Sacks is an ecologist conducting research on the relationship between behaviour and population processes in terrestrial mammals. His work is being conducted in the Wildlife and Ecology Unit of the Veterinary Genetics Laboratory at UC Davis headed by Holly Ernest. Brian Mitchell recently received his $\mathrm{PhD}$ for research on coyote vocal communication. He is now conducting postdoctoral research at the University of Vermont, where he is surveying and modelling the distribution of bird, reptile, and amphibian species. Christen Williams, Wildlife Genetics team leader at the USDA/National Wildlife Research Center, uses genetics to contribute to more effective management of coyotes, black bears, blackbirds, beaver, black vulture, and raccoons. Holly Ernest is a geneticist and veterinarian who uses genomic tools for studies in disease susceptibility, ecology, and forensics in mountain lions, black bears, wild pigs, raptors, and corvids. 